\title{
Silicato de Alumínio em Substrato para Produção de Mudas de Corymbia citriodora
}

\author{
Edicarlos Batista Castro ${ }^{1}$, Leonardo David Tuffi Santos², \\ Luiz Arnaldo Fernandes ${ }^{2}$, Claudio Yukio Tajima ${ }^{3}$ \\ ${ }^{1}$ Departamento de Proteção Vegetal, Universidade Estadual Paulista "Júlio de Mesquita Filho" - UNESP, \\ Botucatu/SP, Brasil \\ ${ }^{2}$ Instituto de Ciências Agrárias, Universidade Federal de Minas Gerais - UFMG, Montes Claros/MG, Brasil \\ ${ }^{3}$ Companhia Brasileira de Lítio - CBL, Unidade Divisa Alegre, Divisa Alegre/MG, Brasil
}

\begin{abstract}
RESUMO
Objetivou-se verificar a eficiência de silicato de alumínio na composição do substrato para produção de mudas de Corymbia citriodora. O delineamento adotado foi o inteiramente casualizado com cinco tratamentos e oito repetições. A composição do substrato consistiu de moinha de carvão, esterco bovino, casca de eucalipto e substrato comercial. Foram acrescidos nos tratamentos 0 (testemunha), 5, 10, 15 e 20\% de silicato de alumínio. O índice de qualidade de mudas, altura, diâmetro do coleto, massa seca e fresca da raiz, área foliar média e total e relação entre massa seca da raiz e massa seca da parte aérea não foram influenciados. Para massa seca e fresca da parte aérea as testemunhas foram superiores 2,5953 e 4,9323 g, respectivamente. Porém a adição de $12,2 \%$ apresentou ganhos crescentes no número de folhas. O silicato de alumínio para produção de mudas de C. citriodora surge como potencial alternativa de destino deste resíduo.
\end{abstract}

Palavras-chave: silício, qualidade de mudas, resíduo industrial, espécie florestal.

\section{Use of Aluminum Silicate Partial Substitution in the Substrate for Seedlings Production Corymbia citriodora}

\begin{abstract}
The aim was to verify the aluminum silicate efficiency on substrate composition for Corymbia citriodora seedlings production. The design was a completely randomized design with five treatments and eight replicates. The composition of the substrate consisted of charcoal powder, bovine manure, eucalyptus husk and commercial substrate. It was added on 0 (evidence), $5,10,15$ and $20 \%$ aluminum silicate in the treatments. The seedling quality index, height, the collar diameter, root fresh and dry mass, mean and full foliar area and ratio between root and aerial part dry mass and were not influenced. For aerial fresh and dry mass the evidence were higher than 2.59 and 4.93 respectively. Nevertheless, the addiction until $12.2 \%$ showed increasing gains on leaves number. The aluminum silicate to produce $C$. citriodoraseedlings emergesas a potential target of this alternative residue.
\end{abstract}

Keywords: silicate, seedling quality, industrial residual, forest species. 


\section{INTRODUÇÃO}

O setor florestal brasileiro possui grande importância para o país e o gênero Corymbia citriodora (Hook.) K.D.Hill \& L.A.S. Johnson têm sido utilizado na formação de florestas plantadas, devido ao rápido crescimento, adaptação a diferentes condições ambientais, as características silviculturais favoráveis ao cultivo e a qualidade de sua madeira (Morais et al., 2010). Esta espécie é amplamente utilizada em reflorestamento para produção de madeira e extração de óleo essencial das folhas para indústria de perfumaria e desinfetantes, sendo também utilizada na arborização de áreas rurais (Lorenzi et al., 2003).

O êxito para um programa de reflorestamento depende de mudas de boa qualidade, capazes de suportar condições adversas no campo após o plantio, além de menor tempo gasto para sua formação completa (Cruz et al., 2004). Assim a produção de mudas configura-se como etapa fundamental para a atividade florestal.

A eficiência na formação de mudas florestais é dependente da qualidade dos substratos, pois exerce função importante no suporte de raízes da planta e influencia diretamente no estabelecimento das mudas no campo (Kämpf, 2000). Um bom substrato deve fornecer nutrientes, umidade e aeração necessária para o ideal crescimento e desenvolvimento das mudas (Cunha et al., 2006).

A utilização de componentes alternativos no preparo dos substratos pode diminuir os custos de produção de mudas e os gastos com insumos externos, porém devem permitir condições adequadas para a espécie. Embora o silicato não seja considerado essencial para o crescimento das plantas, e ainda pouco utilizado na agricultura brasileira, estudos têm mostrado os efeitos benéficos da sua aplicação em espécies acumuladoras como arroz, cana-de-açúcar, cevada, milho, sorgo e trigo (Ma et al., 2001; Gong et al., 2005; Hattori et al., 2005; Sousa et al., 2010; Gong \& Chen, 2012). Plantas consideradas não acumuladoras, como tomate (Lana et al., 2003), pepino (Liang et al., 2005), grão-de-bico (Gunes et al., 2007), girassol (Gunes et al., 2008), morango (Carré-Missio et al., 2010), tremoço (Abdalla, 2011) e batata (Crusciol et al., 2009) têm respondido positivamente a aplicação de Si.
Existem poucas informações sobre quais seriam as melhores fontes de silício a serem utilizadas no cultivo de plantas, porém é importante a identificação de novas alternativas que possibilitem o uso deste elemento na agricultura. O Silicato de Alumínio $\left(\mathrm{Al}_{2} \mathrm{O}_{3} 4 \mathrm{SiO}_{2} \mathrm{H}_{2} \mathrm{O}\right)$ é um resíduo industrial da extração de Lítio do mineral espodumênio após ser submetido à temperatura de $1.200{ }^{\circ} \mathrm{C}$ e ácido sulfúrico $\left(\mathrm{H}_{2} \mathrm{SO}_{4}\right)$.

Com a possibilidade de uso desse resíduo e da importância de sua destinação correta e sustentável, objetivou-se verificar a eficiência de diferentes concentrações de silicato de alumínio na composição de substrato para a produção de mudas de Corymbia citriodora.

\section{MATERIAL E MÉTODOS}

O trabalho foi realizado no Campus do Instituto de Ciências Agrárias da Universidade Federal de Minas Gerais, localizado no município de Montes Claros - MG, em latitude de $16^{\circ} 40^{\prime} 24 \mathrm{~S}$ e longitude $43^{\circ} 50^{\prime} 27 \mathrm{~W}$, a $623 \mathrm{~m}$ de altitude. Segundo a classificação de Köppen o clima da região é do tipo Aw - Tropical de Savana. As temperaturas médias, as umidades relativas e as precipitações observadas ao longo do período experimental foram obtidas em estação meteorológica localizada a aproximadamente $1 \mathrm{~km}$ dos ensaios, e estão representadas na Figura 1.

A semeadura foi realizada em 29 de junho de 2012 e aos 32 dias fez-se o desbaste deixando uma plântula por tubete. Foram semeadas, em média,

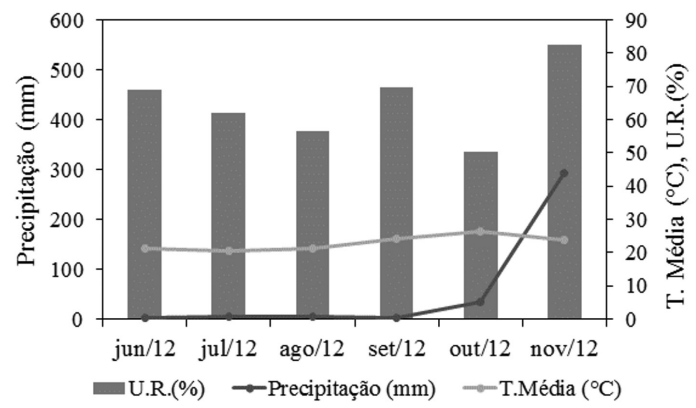

Figura 1. Médias mensais da Temperatura Média $\left({ }^{\circ} \mathrm{C}\right)$, Umidade Relativa (\%) e Precipitação (mm), durante o período de condução dos ensaios.

Figure 1. Mean Temperature $\left({ }^{\circ} \mathrm{C}\right)$, Relative Humidity (\%) and Precipitation (mm) monthly mean during the rehearsals. 
cinco sementes de Corymbia citriodora diretamente em tubetes de $100 \mathrm{~cm}^{3}$, preenchidos com substrato. O substrato utilizado foi composto de $30,3 \%$ de moinha de carvão, 30,3\% de esterco bovino curtido, 9,09\% de casca de eucalipto moída e 30,3\% substrato comercial (BIOPLANT) composto de fibra de pó de coco, casca de pinus, vermiculita, casca de arroz e nutrientes. Foi feita adubação de base com $75 \mathrm{~g}$ de $\mathrm{P}_{2} \mathrm{O}_{5}$ e $15 \mathrm{~g}$ de $\mathrm{K}_{2} \mathrm{O}$ por metro cúbico de substrato, também foram realizadas 3 adubações de cobertura durante o ciclo total das plantas com $100 \mathrm{mg} \mathrm{L}^{-1}$ de $\mathrm{N}$ dissolvido em $2 \mathrm{~L}$ de água. Foram efetuadas irrigações diárias, em média de $20 \mathrm{~mm}$ ao dia, fracionadas em 3 irrigações.

O experimento foi conduzido em viveiro florestal a pleno sol, no delineamento inteiramente casualizado, com cinco tratamentos e oito repetições, sendo cada repetição composta por cinco tubetes. Os tratamentos foram constituídos de doses crescentes de silicato de alumínio adicionadas ao substrato: 0 (testemunha), $5,10,15$ e $20 \%$ do volume. O silicato de alumínio foi fornecido pela Empresa Brasileira de Lítio (CBL), cuja composição química de alguns elementos de interesse para o presente trabalho encontra-se na Tabela 1 .

Após misturar o substrato ao silicato de alumínio antes do plantio das sementes, foi retirado amostras para a caracterização química dos substratos (Tabela 2), conforme Embrapa (1997) e Tedesco et al. (1995).

Aos 146 dias após a semeadura, as mudas foram avaliadas quanto à altura da parte aérea $(\mathrm{H})$, o diâmetro do caule (D), o número de folhas por planta (NF), a área foliar (AF), a massa fresca da parte aérea (MFPA) e a massa fresca das raízes (MFR), por fim a

Tabela 1. Composição química do silicato de alumínio.

Table 1. Chemical composition of aluminum silicate.

\begin{tabular}{|c|c|c|c|c|c|c|c|c|c|c|c|c|}
\hline $\mathrm{SiO}_{2}$ & LiO & $\mathrm{Na}_{2} \mathrm{O}$ & $\mathrm{K}_{2} \mathrm{O}$ & $\mathbf{P}_{2} \mathbf{O}_{5}$ & $\mathrm{CaO}$ & $\mathrm{Al}_{2} \mathrm{O}_{3}$ & $\mathrm{Fe} 2 \mathrm{O3}$ & $\mathrm{CoO}$ & $\mathrm{Mn}_{2} \mathrm{O}_{3}$ & $\mathrm{Cr}_{2} \mathrm{O}_{3}$ & $\mathrm{MgO}$ & \multirow{2}{*}{$\begin{array}{c}\text { Outros } \\
\text { elementos }\end{array}$} \\
\hline & & & & & & $-\%$ & & & & & -- & \\
\hline 64,0 & 1,00 & 0,47 & 0,35 & 0,13 & 3,61 & 18,65 & 0,49 & 0,00 & 0,10 & 0,00 & 0,05 & 11,15 \\
\hline
\end{tabular}

Tabela 2. Características químicas dos substratos em adição com diferentes porcentagens de silicato de alumínio.

Table 2. Substrate chemicals characteristics on the addiction with different percentages of aluminum silicate.

\begin{tabular}{|c|c|c|c|c|c|}
\hline \multirow{2}{*}{ Atributos químicos do substrato* } & \multicolumn{5}{|c|}{ Doses de Silicato de Alumínio (\%) } \\
\hline & $\mathbf{0}$ & 5 & 10 & 15 & 20 \\
\hline pH água & 5,7 & 6,0 & 6,3 & 6,4 & 6,6 \\
\hline P- REM (mg/dm $\left.{ }^{3}\right)$ & 58,6 & 56,5 & 58,6 & 56,5 & 56,5 \\
\hline $\mathrm{P}\left(\mathrm{mg} / \mathrm{dm}^{3}\right)$ & 170,5 & 165,9 & 170,5 & 165,9 & 161,4 \\
\hline $\mathrm{K}\left(\mathrm{mg} / \mathrm{dm}^{3}\right)$ & 490 & 480 & 500 & 500 & 460 \\
\hline $\mathrm{Ca}\left(\mathrm{cmol}_{\mathrm{c}} / \mathrm{dm}^{3}\right)$ & 17,7 & 17 & 16,3 & 15,6 & 14,9 \\
\hline $\operatorname{Mg}\left(\mathrm{cmol}_{\mathrm{c}} / \mathrm{dm}^{3}\right)$ & 1,8 & 2,7 & 2,4 & 2,8 & 1,8 \\
\hline $\mathrm{Al}\left(\mathrm{cmol}_{\mathrm{c}} / \mathrm{dm}^{3}\right)$ & 0,1 & 0 & 0 & 0 & 0 \\
\hline $\mathrm{H}+\mathrm{Al}\left(\mathrm{cmol}_{\mathrm{c}} / \mathrm{dm}^{3}\right)$ & 5,94 & 4,29 & 3,30 & 2,80 & 2,64 \\
\hline $\mathrm{B}\left(\mathrm{cmolc} / \mathrm{dm}^{3}\right)$ & 20,75 & 20,9 & 20 & 19,7 & 17,9 \\
\hline $\mathrm{t}\left(\mathrm{cmol}_{\mathrm{c}} / \mathrm{dm}^{3}\right)$ & 20,85 & 20,9 & 20 & 19,7 & 17,9 \\
\hline $\mathrm{T}\left(\mathrm{cmolc} / \mathrm{dm}^{3}\right)$ & 26,69 & 25,19 & 23,30 & 22,5 & 20,54 \\
\hline $\mathrm{V}(\%)$ & 78 & 83 & 86 & 88 & 87 \\
\hline m (\%) & 0 & 0 & 0 & 0 & 0 \\
\hline $\mathrm{B}\left(\mathrm{mg} / \mathrm{dm}^{3}\right)$ & 2,2 & 1,4 & 1,1 & 1,4 & 0,7 \\
\hline $\mathrm{Zn}\left(\mathrm{mg} / \mathrm{dm}^{3}\right)$ & 15,5 & 14,3 & 15 & 16,4 & 15,7 \\
\hline $\mathrm{Fe}\left(\mathrm{mg} / \mathrm{dm}^{3}\right)$ & 86,9 & 60,0 & 76,2 & 69,0 & 83,3 \\
\hline $\operatorname{Mn}\left(\mathrm{mg} / \mathrm{dm}^{3}\right)$ & 66,2 & 33,0 & 53,7 & 67,0 & 55,3 \\
\hline $\mathrm{Cu}\left(\mathrm{mg} / \mathrm{dm}^{3}\right)$ & 0,6 & 0,6 & 0,6 & 0,5 & 0,7 \\
\hline Mat. Org. (dag/kg) & 8,5 & 7,9 & 8,5 & 7,5 & 7,5 \\
\hline
\end{tabular}

${ }^{*} \mathrm{P}-\mathrm{REM}=$ fósforo remanescente. $\mathrm{P}$ = fósforo disponível; $\mathrm{K}$ = potássio trocável; $\mathrm{Ca}$ = cálcio trocável; $\mathrm{Mg}=$ magnésio trocável; $\mathrm{Al}=$ alumínio trocável; $\mathrm{S}=$ enxofre disponível; $\mathrm{H}+\mathrm{Al}=$ acidez potencial; $\mathrm{SB}=$ soma de bases; $\mathrm{t}=\mathrm{CTC}$ efetiva; $\mathrm{T}=\mathrm{CTC} \mathrm{pH}$; $\mathrm{V}=$ saturação por bases; $\mathrm{m}=$ saturação por alumínio $((\mathrm{Al} / \mathrm{CTCt}) \mathrm{x} 100) ; \mathrm{B}=$ boro disponível; $\mathrm{Zn}=$ zinco disponível; $\mathrm{Fe}=$ ferro disponível; $\mathrm{Mn}=$ manganês disponível; $\mathrm{Cu}=$ cobre disponível; Mat. Org. = matéria orgânica. 
massa seca da parte aérea (MSPA) e a massa seca das raízes (MSR). A altura das mudas foi medida a partir do coleto até o ápice da planta com régua graduada. O diâmetro foi aferido a dois centímetros do substrato com paquímetro digital. Em seguida procedeu-se a contagem do número de folhas por planta. As mudas foram cortadas rente ao substrato e coletadas as folhas de $20 \%$ das plantas de cada tratamento. As folhas foram digitalizadas e submetidas à análise de imagens, com auxílio do software Image-Pro Plus, versão 4.1, para Windows $^{\circledR}$ (Media Cybernetics, Silver Spring, MD, USA), para cálculo da área média foliar e a área foliar por muda (Sant'Anna-Santos et al., 2012).

As raízes das mudas foram lavadas em água corrente, de modo a eliminar todo o substrato. A parte aérea e as raízes foram pesadas para determinação da massa fresca e posteriormente secas em estufa a $60^{\circ} \mathrm{C}$, até peso constante, para a determinação de sua massa seca. Foi utilizada relação MSR/MSPA obtida pela relação entre parte aérea/sistema radicular

H, D, MSPA e a PMSR foram utilizados para determinação do índice de qualidade de Dickson (IQD) (Dickson et al., 1960), conforme a Equação 1:

$$
I Q D=\frac{M S T}{\frac{H}{D}+\frac{M S P A}{M S R}}
$$

onde: $\mathrm{IQD}=$ índice de qualidade de muda, $\mathrm{MST}=$ massa seca total, $\mathrm{H}=$ altura, $\mathrm{D}=$ Diâmetro, $\mathrm{MSPA}=$ massa seca da parte aérea e $\mathrm{MSR}=$ massa seca da raiz.

Os resultados foram submetidos à análise de variância e, quando significativo, ajustadas regressões em função das doses de silicato de alumínio, ambos a $5 \%$ de probabilidade.

\section{RESULTADOS E DISCUSSÃO}

A altura, o diâmetro, a massa seca e fresca das raízes, o IQD, a massa seca da raiz pela massa seca da parte aérea e a área foliar média e total não foram influenciadas pela adição de silicato de alumínio no substrato, independentemente da dose utilizada (Tabela 3).

Os valores observados para altura das mudas de $C$. citriodora são considerados adequados para mudas de eucalipto (Mafia et al., 2005). Esta variável é considerada como uma das mais antigas para classificação e seleção de mudas, que combinadas com o diâmetro do coleto tornam-se importantes parâmetros morfológicos na avaliação do crescimento das plantas (Parviainen, 1981; Carneiro, 1995). Gomes et al. (1996) estabeleceram um valor mínimo de diâmetro de coleto de $2 \mathrm{~mm}$ e Lopes et al. (2007), de 2,5 mm para plantio de mudas de Eucalyptus grandis.

Freitas et al. (2006) e Richards (1977) evidenciaram que a restrição no crescimento do sistema radicular, influencia a área foliar em sistemas de produção de mudas de eucalipto de modo a favorecer um desenvolvimento mais equilibrado. Portanto, como o sistema radicular não foi significativo para as doses de silicato de alumínio testadas nos substratos, também foi possível observar que, a área foliar média e total das mudas seguiram o mesmo padrão. Os resultados relativos à massa da matéria seca total da planta obtidos nessa pesquisa

Tabela 3. Parâmetros morfológicos de mudas de Corymbia citriodora em função da adição de diferentes concentrações de silicato de alumínio no substrato, aos 146 dias após a semeadura.

Table 3. Morphological parameters Corymbia citriodora seedlings growth versus the addiction of different aluminum silicate concentrations on substrate, at 146 days after transplanting.

\begin{tabular}{|c|c|c|c|c|c|c|c|c|}
\hline DOSES & $\mathbf{H}$ & D & MSR & MFR & IQD & $\begin{array}{l}\text { MSR/ } \\
\text { MSPA }\end{array}$ & AFT & AFM \\
\hline --- \% --- & \multicolumn{2}{|c|}{ - cm planta ${ }^{-1}$} & \multicolumn{4}{|c|}{------------- g planta ${ }^{-1}$} & \multicolumn{2}{|c|}{------ $\mathbf{c m}^{2}------$} \\
\hline 0 & 21,90 & 2,58 & 1,10 & 1,75 & 0,34 & 0,42 & 153,38 & 9,34 \\
\hline 5 & 20,78 & 2,50 & 1,17 & 1,95 & 0,34 & 0,51 & 152,61 & 9,2 \\
\hline 10 & 22,02 & 2,58 & 1,09 & 1,94 & 0,32 & 0,48 & 146,45 & 8,92 \\
\hline 15 & 22,13 & 2,53 & 1,17 & 1,97 & 0,34 & 0,48 & 149,33 & 8,76 \\
\hline 20 & 22,91 & 2,43 & 1,10 & 1,80 & 0,30 & 0,48 & 135,45 & 7,84 \\
\hline $\mathrm{F}$ & $1,49^{\text {ns }}$ & $0,55^{\mathrm{ns}}$ & $0,68^{\text {ns }}$ & $1,67^{\mathrm{ns}}$ & $2,60^{\text {ns }}$ & $1,94^{\mathrm{ns}}$ & $0,77^{\text {ns }}$ & $1,40^{\text {ns }}$ \\
\hline CV (\%) & 8,07 & 9,42 & 11,62 & 11,60 & 10,84 & 14,19 & 15,85 & 16,08 \\
\hline
\end{tabular}

Altura (H), diâmetro (D), massa seca da parte aérea (MSPA), massa seca da raiz (MSR), massa fresca da parte aérea (MFPA), massa

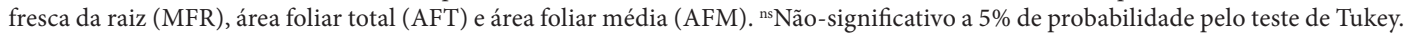


foram acima de $3 \mathrm{~g} /$ planta. Segundo Gomes \& Paiva (2004) e Paiva et al. (2009) a produção de biomassa seca total, apesar de ser um método destrutivo, é bastante consistente na avaliação das respostas à adubação em espécies vegetais e indica capacidade de resistência das mudas a condições de campo.

É possível observar que em todos os tratamentos as mudas de $C$. citriodora apresentaram médias acima de 0,30 para o índice de Dickson, desta forma o substrato nas diferentes porcentagens de silicato de alumínio proporcionou qualidade de acordo com o padrão estabelecido por Hunt (1990) para mudas produzidas em tubetes de $50 \mathrm{~mL}$, além disso, é possível que os tubetes de $100 \mathrm{~mL}$ tenham contribuído para o maior IQD por possibilitarem maior diâmetro das mudas, evitar o estiolamento devido a menor densidade de plantas por área, e por fim, maior produção de massa de matéria seca. Segundo esse autor, são considerados adequados valores para o índice de Dickson superiores a 0,20. Além de indicador da qualidade das mudas, considera vigor e o equilíbrio da distribuição da biomassa na muda (Vidal et al., 2006).

A relação entre a massa seca da raiz (MSR) e massa seca da parte aérea (MSPA) das mudas, segundo Caldeira et al. (2000), deve ser de 0,5 para mudas de eucalipto produzidos em tubetes de $50 \mathrm{~cm}^{3}$. Mudas que apresentam grande produção de biomassa radicular são mais aptas a condições de estresse ambiental após o plantio, por possuírem maior facilidade de sustentação, além de maior superfície e eficiência para absorção de água e nutrientes (Freitas et al., 2005).

A MSPA, MFPA e NF foram ajustados segundo modelo de regressão quadrático em função das concentrações de silicato de alumínio no substrato (Figuras 2 e 3 ). A massa seca da parte aérea das plantas de C. citriodora, apresentou comportamento semelhante. Observou-se leve tendência de redução da produção de MSPA e MFPA com o aumento das proporções de silicato de alumínio. A produção de MSPA variou de 2,59 g na testemunha para 2,38 g com $20 \%$ de silicato, ou seja, uma redução de $8 \%$. Entretanto, a produção da MFPA variou de 4,9323 g na testemunha para 4,41 quando se utilizou $20 \%$ de silicato de alumínio, ocorrendo uma redução de 11\% (Figura 2 ).

Embora responsivo ao $\mathrm{Si}$, o eucalipto, à semelhança da maioria das dicotiledôneas (Marschner, 1995), não é uma planta que acumula grandes quantidades do elemento. Segundo Carvalho et al. (2003), na fase inicial

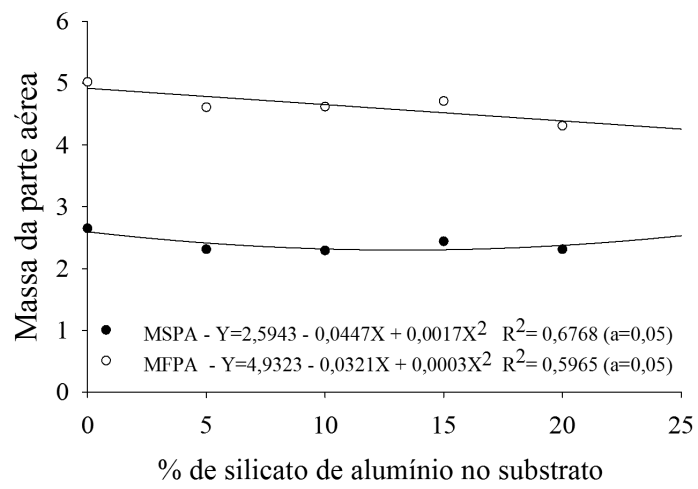

Figura 2. Massa da parte aérea de mudas Corymbia citriodora em função da adição de silicato de alumínio no substrato. MSPA = Massa seca da parte aérea; MFPA = Massa fresca da parte aérea.

Figure 2. Aerial mass part of the Corymbia citriodora seedling versus the addiction of aluminum silicate on substrate. (APDM) = Aerial part dry mass; $(\mathrm{APFM})=$ Aerial part fresh mass.

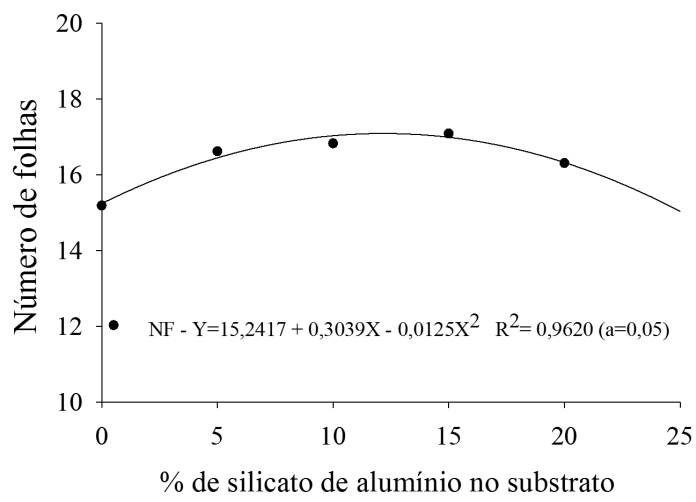

Figura 3. Número de folhas (NF) de mudas de Corymbia citriodora em função da adição de silicato de alumínio no substrato.

Figure 3. Corymbia citriodora seedling leaves number (LN) versus the addiction of aluminum silicate to substrate.

de crescimento, as plantas de eucalipto absorvem pouco $\mathrm{Si}$, sugerindo possuírem um mecanismo de exclusão do mesmo. Pressupõe-se, portanto, ser mínimo o papel do Si no eucalipto o que, aparentemente, o desqualifica como responsável pela produção de MSPA das plantas (Carvalho et al., 2001).

A adição de silicato de alumínio no substrato apresentou maior do número de folhas em plantas de C. citriodora. Observa-se média de 17,09 folhas para a concentração de 12,2\%. Esses resultados refletem o benefício proporcionado pela adição de silicato de 
alumínio no substrato. Entretanto, a partir de 12,2\% do composto observou-se redução nos números de folhas (Figura 3).

A presença do elemento silício $(\mathrm{Si})$ mesmo em pequenas quantidades como no caso de plantas de eucalipto, constituinte do silicato de alumínio, pode estar relacionada com a maior quantidade de folhas nas mudas de C. citriodora por diminuir a senescência desse órgão. De acordo com Epstein (1994) e Marschner (2012), o Si beneficia direta e indiretamente as plantas e pode proporcionar o crescimento e produção vegetal. $\mathrm{Na}$ presença deste elemento as folhas se tornam mais eretas, fato este relacionado com aumento do teor de hemicelulose e lignina nas folhas que tornam os tecidos mais rígidos, como foi observado em estudo realizado com aveia (Hossain et al., 2007). Desta forma, as plantas apresentam menor sombreamento e maior proteção aos fatores externos.

Os silicatos de modo geral podem melhorar o desenvolvimento das plantas, o que indiretamente influencia as condições físicas do solo, além de comportar-se de maneira similar aos carbonatos no solo, sendo capazes de elevar o $\mathrm{pH}$, neutralizando o $\mathrm{Al}$ trocável e outros elementos tóxicos (Maio et al., 2011).

\section{CONCLUSÕES}

A utilização do silicato de alumínio ao substrato para produção de mudas de Corymbia citriodora surge como alternativa de destino adequado deste resíduo.

A utilização de $12,2 \%$ de silicato de alumínio mostrou-se eficiente no aumento do número de folhas das mudas de C. citriodora, além de ter proporcionado condições favoráveis ao desenvolvimento das plantas.

\section{STATUS DA SUBMISSÃO}

Recebido: 29 jul., 2014

Aceito: 6 ago., 2015

\section{AUTOR(ES) PARA CORRESPONDÊNCIA}

\section{Edicarlos Batista Castro}

Departamento de Proteção Vegetal, Universidade Estadual Paulista "Júlio de Mesquita Filho" UNESP, CP 237, CEP 18610-307, Botucatu, SP, Brasil

e-mail: castroeb@hotmail.com

\section{REFERÊNCIAS}

Abdalla MM. Beneficial effects of diatomite on growth, the biochemical contents and polymorphic DNA in Lupinus albus plants grown under water stress. Agriculture and Biology Journal of North America 2011; 2011(2): 207-220. http://dx.doi.org/10.5251/abjna.2011.2.2.207.220.

Caldeira MVW, Schumacher MV, Barrichelo LR, Voget HLM, Oliveira LS. Crescimento de mudas de Eucalyptus saligna Smith em função de diferentes doses de vermicomposto. Floresta 2000; 28(1/2): 19-30.

Carneiro JGA. Produção e controle de qualidade de mudas florestais. Curitiba: Universidade Federal do Paraná; 1995. $451 \mathrm{p}$.

Carré-missio V, Rodrigues FÁ, Schurt DA, Rezende DC, Ribeiro NB, Zambolim L. Aplicação foliar de silicato de potássio, acibenzolar-S-metil e fungicidas na redução da mancha de Pestalotia em morango. Tropical Plant Pathology 2010; 35: 182-185.

Carvalho R, Furtini AE No, Curi N, Resende AV. Absorção e translocação de silício em mudas de eucalipto cultivadas em latossolo e cambissolo. Ciência e Agrotecnologia 2003; 27(3): 491-500. http://dx.doi.org/10.1590/S141370542003000300001 .

Carvalho R, Furtini AE No, Santos CD, Fernandes LA, Curi N, Rodrigues DC. Interações silício-fósforo em solos cultivados com eucalipto em casa-de-vegetação. Pesquisa Agropecuária Brasileira 2001; 36(3): 557-565. http://dx.doi.org/10.1590/S0100-204X2001000300022.

Crusciol CAC, Pulz AL, Lemos LB, Soratto RP, Lima GPP. Effects of silicon and drought stress on tuber yield and leaf biochemical characteristics in potato. Crop Science 2009; 49(3): 949-954. http://dx.doi.org/10.2135/ cropsci2008.04.0233.

Cruz CAF, Paiva HN, Gomes KCO, Guerrero CRA. Efeito de diferentes níveis de saturação por bases no desenvolvimento e qualidade de mudas de ipê-roxo (Tabebuia impetiginosa (Mart.) Standley). Scientia Florestalis 2004; 66: 100-107.

Cunha AM, Cunha GM, Sarmento RA, Cunha GM, Amaral JFT. Efeito de diferentes substratos sobre o desenvolvimento de mudas de Acacia sp. Revista Árvore 2006; 30(2): 207-214. http://dx.doi.org/10.1590/S010067622006000200007 .

Dickson A, Leaf AL, Hosner JF. Quality appraisal of white spruce and white pine seedling stock in nurseries. Forestry Chronicle 1960; 36(1): 10-13. http://dx.doi.org/10.5558/ tfc36010-1.

Empresa Brasileira de Pesquisa Agropecuária - EMBRAPA. Centro Nacional de Pesquisa de Solos. Manual de métodos de análise de solo. 2. ed. Rio de Janeiro; 1997. 212 p. EMBRAPA-CNPS Documentos n. 1.

Epstein E. The anomaly of silicon in plant biology. Proceedings of the National Academy of Sciences of the 
United States of America 1994; 91(1): 11-17. http://dx.doi. org/10.1073/pnas.91.1.11. PMid:11607449.

Freitas TAS, Barroso DG, Carneiro JGA, Penchel RM, Figueiredo FAMMA. Mudas de eucalipto produzidas a partir de miniestacas em diferentes recipientes e substratos. Revista Árvore 2006; 30(4): 519-528. http:// dx.doi.org/10.1590/S0100-67622006000400004.

Freitas TAS, Barroso DG, Carneiro JGA, Penchel RM, Lamônica KR, Ferreira DAF. Desempenho radicular de mudas de eucalipto produzidas em diferentes recipientes e substratos. Revista Árvore 2005; 29(6): 853-861. http:// dx.doi.org/10.1590/S0100-67622005000600003.

Gomes JM, Paiva HN, Couto L. Produção de mudas de eucalipto. Informe Agropecuário 1996; 18(185): 15-22.

Gomes JM, Paiva HN. Viveiros florestais: propagação sexuada. Viçosa: Editora UFV; 2004. 11 p. Caderno Didático n. 72

Gong HJ, Chen KM. The regulatory role of silicon on water relations, photosynthetic gas exchange, and carboxylation activities of wheat leaves in field drought conditions. Acta Physiologiae Plantarum 2012; 33: 1-6.

Gong HJ, Zhu XY, Chen KM, Wang SM, Zhang CG. Silicon alleviates oxidative damage of wheat plants in pots under drought. Plant Science 2005; 169(2): 313-321. http://dx.doi.org/10.1016/j.plantsci.2005.02.023.

Gunes A, Pilbeam DJ, Inal A, Bagci EG, Coban S. Influence of silicon on antioxidant mechanisms and lipid peroxidation in chickpea (Cicer arietinum L.) cultivars under drought stress. Journal of Plant Interactions 2007; 2(2): 105-113. http://dx.doi.org/10.1080/17429140701529399.

Gunes A, Pilbeam DJ, Inal A, Coban S. Influence of silicon on sunflower cultivars under drought stress. I: Growth, antioxidant mechanisms, and lipid peroxidation. Communications in Soil Science and Plant Analysis 2008; 39(13-14): 1885-1903. http://dx.doi.org/10.1080/00103620802134651.

Hattori T, Inanaga S, Araki H, Ping A, Morita S, Luxova $\mathrm{M}$ et al. Application of silicon enhanced drought tolerance in Sorghum bicolor. Physiologia Plantarum 2005; 123(4): 459-466. http://dx.doi.org/10.1111/j.1399-3054.2005.00481.x.

Hossain MT, Soga K, Wakabayashi K, Kamisaka S, Fujii S, Yamamoto R et al. Modification of chemical properties of cell walls by silicon and its role in regulation of the cell wall extensibility in oat leaves. Journal of Plant Physiology 2007; 164(4): 385-393. http://dx.doi.org/10.1016/j. jplph.2006.02.003. PMid:16618521.

Hunt GA. Effect of styroblock design and cooper treatment on morphology of conifer seedlings. In: Proceedings of the Target Seedling Symposium, Meeting of the Western Forest Nursery Associations; 1990; Roseburg. Fort Collins: United States Departament of Agriculture, Forest Service; 1990. p. 218-222. General Technichal Report n. RM-200.

Kämpf AN. Seleção de materiais para uso como substrato. In: Kämpf AN, Fermino MH, editores. Substratos para plantas: a base da produção vegetal em recipientes. Porto Alegre: Gênesis: 2000. p. 139-145.

Lana RMQ, Korndörfer GH, Zanão Júnior LA, Silva AF, Lana AMQ. Efeito do silicato de cálcio sobre a produtividade e acumulação de silício no tomateiro. Bioscience Journal 2003; 19: 15-20.

Liang YC, Sun WC, Si J, Römheld V. Effects of foliar and root applied silicon on the enhancement of induced resistance to powdery mildew in Cucumis sativus. Plant Pathology 2005; 54(5): 678-685. http://dx.doi.org/10.1111/j.13653059.2005.01246.x.

Lopes JLW, Guerrini IA, Saad JCC. Qualidade de mudas de eucalipto produzidas sob diferentes lâminas de irrigação e dois tipos de substrato. Revista Árvore 2007; 31(5): 835843. http://dx.doi.org/10.1590/S0100-67622007000500007.

Lorenzi H, Souza HM, Torres MAV, Bacher LB. Árvores exóticas no Brasil: madeireiras, ornamentais e aromáticas. Nova Odessa: Instituto Plantarum; 2003. 368 p.

Ma JF, Miyake Y, Takahashi E. Silicon as a beneficial element for crop plants. In: Datnoff LE, Snyder GH, Korndörfer GH, editores. Silicon in agriculture. Amsterdam: Elsevier; 2001.p. 17-39. http://dx.doi.org/10.1016/S09283420(01)80006-9.

Mafia RG, Alfenas AC, Siqueira L, Ferreira EM, Leite HG, Cavallazzi JRP. Critério técnico para determinação da idade ótima de mudas de eucalipto para plantio. Revista Árvore 2005; 29(6): 947-953. http://dx.doi.org/10.1590/ S0100-67622005000600014.

Maio MM, Sampaio RA, Nascimento AL, Prates FBS, Rodrigues MN, Silva HP et al. Atributos físicos do solo, adubado com lodo de esgoto e silicato de cálcio e magnésio. Revista Ceres 2011; 58(6): 823-830. http:// dx.doi.org/10.1590/S0034-737X2011000600021.

Marschner H. Mineral nutrition of higher plants. 2. ed. London: Academic Press; 1995.

Marschner H. Mineral nutrition of higher plants. 3. ed. London Academic Press; 2012.

Morais E, Zanotto ACS, Freitas MLM, Moraes MLT, Sebbenn AM. Variação genética, interação genótipo solo e ganhos na seleção em teste de progênies de Corymbia citriodora Hook em Luiz Antonio, São Paulo. Scientia Forestalis 2010; 38(85): 11-18.

Paiva AV, Poffiani F, Gonçalves JLM, Ferraz AV. Crescimento de mudas de espécies arbóreas nativas, adubadas com diferentes doses de lodo de esgoto seco e com fertilização mineral. Scientia Florestalis 2009; 37(84): 499-511.

Parviainen JV. Qualidade e avaliação de qualidade de mudas florestais. In: Anais do Seminário de Sementes e Viveiros Florestais; 1981; Curitiba. Paraná: FUPEF; 1981. p. 59-90.

Richards D. Root shoot interaction: a functional equilibrium for water uptake in peach (Prunus percica L.botoch). Annals of Botany 1977; 41: 279-281. 
Sant'Anna-Santos BF, Azevedo AA, Silva LC, Oliva MA. Diagnostic and prognostic characteristics of phytotoxicity caused by fluoride on Spondias dulcis Forst. F. (Anacardiaceae). Anais da Academia Brasileira de Ciências 2012; 84(3): 689-702. http://dx.doi.org/10.1590/ S0001-37652012005000048. PMid:22832541.

Sousa JV, Rodrigues CR, Luz JMQ, Sousa VBF, Carvalho PC, Rodrigues TM et al. Silicato de potássio via foliar no milho: fotossíntese, crescimento e produtividade. Bioscience Journal 2010; 26: 502-513.
Tedesco MJ, Gianello C, Bissani CA, Bohnen H, Volkweiss SJ. Análise de solo, plantas e outros materiais. 2. ed. Porto Alegre: Universidade Federal do Rio Grande do Sul; 1995. 147 p. Boletim Técnico n. 5.

Vidal LHI, Souza JRP, Fonseca EP, Bordin I. Qualidade de mudas de guaco produzidas por estaquia em casca de arroz carbonizada com vermicomposto. Horticultura Brasileira 2006; 24(1): 26-30. http://dx.doi.org/10.1590/ S0102-05362006000100006. 